\title{
An exercise challenge protocol for epidemiological studies of asthma in children: comparison with histamine challenge
}

\author{
M.M. Haby*, S.D. Anderson**, J.K. Peat*, C.M. Mellis+, B.G. Toelle*, A.J. Woolcock*
}

\begin{abstract}
An exercise challenge protocol for epidemiological studies of asthma in children: comparison with histamine challenge. M.M. Haby, S.D. Anderson, J.K. Peat, C.M. Mellis, B.G. Toelle, A.J. Woolcock. CERS Journals Ltd 1994.

ABSTRACT: We investigated whether an exercise challenge protocol is suitable for measuring bronchial responsiveness in epidemiological studies of asthma in children, and determined its comparability with histamine challenge.

The exercise challenge was 6 minutes of outdoor, free-range running at 85-90\% of maximum heart rate, measured by heart rate monitor. Nose clips were worn. Distance run was measured to estimate oxygen consumption. Water content of the inspired air was $<10 \mathrm{mg} \mathrm{H} \mathrm{H}_{2} \mathrm{O} \cdot l^{-1}$. Histamine challenge was by the rapid method. We used questionnaires to measure respiratory symptoms and skin prick tests to measure atopy.

A total of 96 children aged 8-11 years were studied. Bronchial hyperresponsiveness (BHR) to exercise challenge was defined as a fall in forced expiratory volume in one second $\left(\mathrm{FEV}_{1}\right)$ of $13 \%$ or greater. Eleven children had a positive response to exercise challenge and 11 to histamine challenge but 12 responded to one challenge and not to the other. The correlation coefficient between the two tests was $0.65(p=0.0001)$.

Exercise challenge thus proved to be a practical epidemiological tool for objective measurements of bronchial responsiveness in children. In this sample, some children responded to one challenge and not to the other which suggests that the two challenges identify different abnormalities of the airways.

Eur Respir J., 1994, 7, 43-49.
\end{abstract}

Although bronchial responsiveness is usually measured in the field with histamine or methacholine $[1,2]$, exercise challenge is also potentially useful in epidemiological studies of children because it simulates the real-life circumstances of an acute episode of airway narrowing. Studies in the laboratory suggest that some children with asthmatic symptoms respond to an exercise challenge but not to methacholine or histamine and vice versa [3-6]. However, the concordance between positive responses to exercise and to histamine or methacholine in field studies has not been documented. Furthermore, exercise may be more specific than methacholine for distinguishing asthma from chronic lung disease [7]. Although exercise challenge has been standardised for use in the laboratory $[8,9]$, it has not been standardised for use as an epidemiological tool.

An exercise challenge has been used in several epidemiological studies [10-14], but limitations in the methods used may have affected the sensitivity of the test. Four studies did not measure exercise intensity [10,11, 13, 14], four studies did not document weather conditions [10, 11, 13, 14] and none used nose clips to ensure mouth breathing. Also, four of the five studies used measurements of peak expiratory flow (PEF) rather than of forced expiratory volume in one second $\left(\mathrm{FEV}_{1}\right)$ [10-13]. This may have reduced the repeatability of the test because PEF has more within-subject variability than the $\operatorname{FEV}_{1}[15,16]$.
*Department of Medicine, University of Sydney; **Respiratory Medicine; and +Epidemiology Unit, Institute of Respiratory Medicine, Royal Prince Alfred Hospital.

Correspondence. M.M. Haby

c/o A.J. Woolcock, Institute of Respiratory Medicine

Royal Prince Alfred Hospital

Camperdown NSW 2050

Australia

Keywords: Asthma

bronchial hyperreactivity

bronchial provocation tests

child

epidemiology

exercise challenge

Received: February 231993

Accepted after revision July 201993
An exercise protocol which has good sensitivity could be widely used as a standard protocol to compare bronchial responsiveness in populations of children. In this paper, we describe a protocol for exercise challenge which is designed to overcome the methodological limitations of challenges used in previous epidemiological studies. To test the suitability of this exercise challenge for epidemiological studies, we have compared it with a histamine challenge and with other data relating to asthma (recent wheeze, atopy and doctor diagnosed asthma).

\section{Methods}

\section{Subjects and Study Design}

A cross-sectional sample of children was selected by inviting all those in grades 3, 4 and 5 (aged 8-11 yrs) at Belmont Primary School to attend for histamine challenge testing. Belmont, which has a humid temperate climate, is a town of 20,000 people on the New South Wales coast. A letter requesting consent for the child to have skin prick tests and histamine challenge was sent home with a questionnaire to parents/guardians for completion prior to study. At the first study, skin prick tests, height and weight 
measurements and lung function tests were conducted and the histamine challenge administered. Following this, parents were asked to consent to the child undergoing an exercise challenge, which was administered less than 7 days later. Parental consent to the histamine challenge was $73 \%$ (137/188). Letters asking for consent to exercise were distributed to the parents of 130 of the children tested with histamine challenge, of whom $75 \%$ (98/130) of parents consented. A total of 96 children participated in both the histamine and exercise challenge, of whom 2 children had technically unsatisfactory data for either challenge and were excluded from analyses.

All subjects had satisfactory baseline lung function $\left(\mathrm{FEV}_{1}\right)$ for the challenges, i.e. $>75 \%$ of their predicted value before exercise challenge and $>60 \%$ of their predicted value before histamine challenge. All tests were conducted by the same team of research assistants.

These studies were approved by the Human Ethics Committee of the University of Sydney.

\section{Non-attenders:}

A survey of the non-attenders for histamine challenge showed that $13 \%$ had used an asthma medication in the last month compared to $18 \%$ of the attenders. For exercise challenge, $13 \%$ of non-attenders and $21 \%$ of attenders had used an asthma medication in the last month. Although these percentages were not significantly different from one another at the $\mathrm{p}<0.05$ level, they suggest that children with asthma may have been more likely to attend for testing.

\section{Lung function tests}

Forced vital capacity (FVC), forced expiratory volume in one second $\left(\mathrm{FEV}_{1}\right)$ and peak expiratory flow (PEF) were measured on the same manoeuvre with Mijnhardt VRS 2000 dry rolling seal spirometers (Mijnhardt B.V., Bunnik, Holland) connected to IBM compatible laptop computers running Scientific and Medical (S\&M Instrument Company Inc., Doylestown, PA) data acquisition software. The calibration of each spirometer was checked weekly but did not need adjustment. All lung function tests were performed with the child standing and without a noseclip. Children were instructed to take a big, deep breath and then to blow out as hard and as fast as they could. Forced expiratory manoeuvres were repeated until two measurements of $\mathrm{FEV}_{1}$ within $100 \mathrm{ml}$ of each other were obtained. The largest $\mathrm{FEV}_{1}$ was used in analyses. Predicted values of FVC and $\mathrm{FEV}_{1}$ were based on height and sex and calculated from normal values obtained using the same equipment for 1,280 Australian children without asthma, not using asthma medications, with no recent respiratory infection, and who were not treated for bronchitis before the age of 2 years. The regression equation for normal FVC was:

FVC $=1.23 \times 10^{-4} \times$ height $^{2}-0.261 \quad(-0.147$ for females $)$. and for $\mathrm{FEV}_{1}$ was:

$$
\mathrm{FEV}_{1}=1.06 \times 10^{-4} \times \text { height }^{2}-0.155 \quad(-0.09 \text { for females }) \text {. }
$$

\section{Bronchial responsiveness}

Salbutamol was withheld for $6 \mathrm{~h}$ prior to each histamine or exercise challenge test. For exercise challenge only, sodium cromoglycate was also withheld for $6 \mathrm{~h}$. Children who had an $\mathrm{FEV}_{1}$ less than $75 \%$ of predicted prior to exercise challenge or an $\mathrm{FEV}_{1}$ less than $60 \%$ of predicted prior to histamine challenge were excluded from having the challenge test.

(i) Exercise challenge. Ambient temperature and relative humidity were recorded prior to each subject being tested because, if the absolute water content was above $10 \mathrm{mg}$ $\mathrm{H}_{2} \mathrm{O} \cdot l^{-1}[17,18]$ (fig. 1), testing would have to be postponed until conditions were suitable. After baseline lung function was measured, children underwent a 6 min run on a $100 \mathrm{~m}$ track on a flat, grassed oval marked with cones spaced $10 \mathrm{~m}$ apart. Each subject wore a nose-clip to ensure mouth-breathing and a Polar Accurex heart rate monitor (Polar Electro, Hakamaantie, Finland) for the duration of the run. Heart rate was recorded at one minute intervals. Children were encouraged to run at an intensity which gave a heart rate of $85-90 \%$ of their predicted maximum [17], which is approximately $180-190$ beats per minute (bpm) for 8-11 year olds, and to maintain a heart rate of $180 \pm 10 \mathrm{bpm}$ for the final $4 \mathrm{~min}$ of exercise. The distance run by each child was measured so that oxygen consumption could be estimated [19]. Following the exercise challenge, measurements of lung function were made at 3,5 and 10 min. Forced expiratory manoeuvres were repeated until two measurements of $\mathrm{FEV}_{1}$ within $100 \mathrm{ml}$ of each other were obtained, of which the larger value was used in analyses. If $\mathrm{FEV}_{1}$ fell by more than $40 \%$ of the baseline value the post-exercise measurements were stopped and $200 \mu \mathrm{g}$ salbutamol aerosol administered. Children with a fall in $\mathrm{FEV}_{1}$ greater than $10 \%$ following the final reading were given $200 \mu \mathrm{g}$ salbutamol aerosol to aid recovery. Bronchial

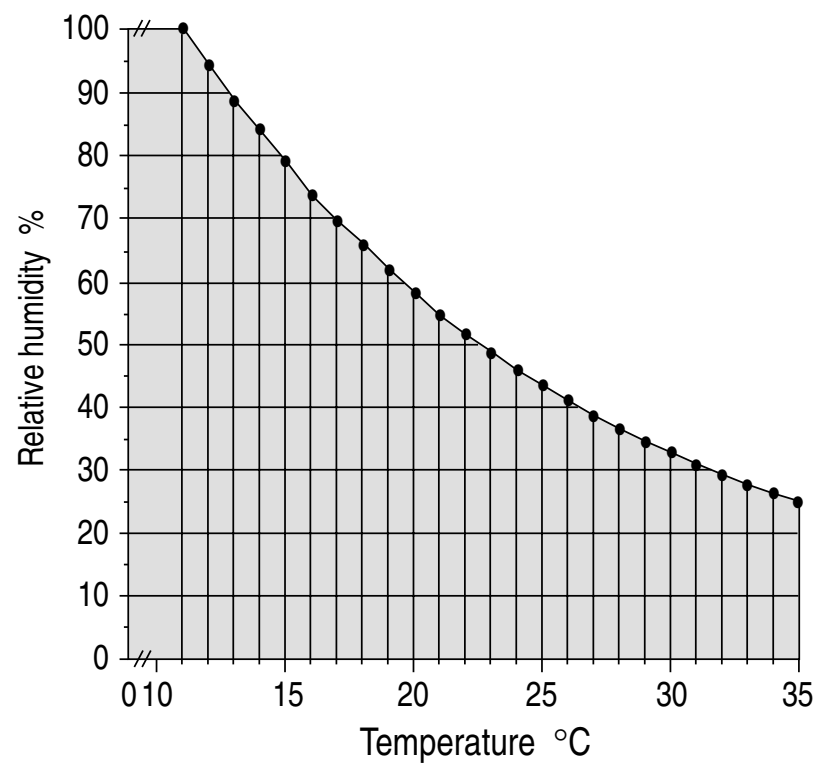

Fig. 1. - Relationship between ambient temperature and relative humidity at an absolute water content of $10 \mathrm{mg} \mathrm{H}_{2} \mathrm{O} \cdot l^{-1}$ of air. The shaded area represents weather conditions which are suitable for exercise challenge [30]. 
hyperresponsiveness (BHR) to exercise was defined as a fall in $\mathrm{FEV}_{1}$ of $13 \%$ or more following exercise challenge. This was calculated by determining the upper limit of normal for \% fall in $\mathrm{FEV}_{1}$, namely a value equal to $1.96 \mathrm{SD}$ above the mean \% fall in $\mathrm{FEV}_{1}$ in 'normal' subjects. "Normal' was defined as subjects without diagnosed asthma, recent wheeze or atopy.

(ii) Histamine challenge. Bronchial responsiveness to histamine was measured using the rapid method of YAN et al. [20]. After baseline lung function was recorded, two puffs of saline were administered as a control dose and lung function was recorded again. Histamine acid phosphate was then administered by use of DeVilbiss hand-held (No. 45) nebulisers in doubling doses ranging from 0.06 to 3.9 $\mu$ mol histamine. Lung function was measured following each dose. Forced expiratory manoeuvres were repeated until two measurements of $\mathrm{FEV}_{1}$ within $100 \mathrm{ml}$ of each other were obtained, of which the larger value was used in analyses. The test was stopped if there was a fall in $\mathrm{FEV}_{1}$ of $20 \%$ or more or when all histamine dose steps to 3.9 $\mu$ mol had been administered. Children with a fall in $\mathrm{FEV}_{1}$ greater than $10 \%$ were given $200 \mu \mathrm{g}$ salbutamol aerosol to aid recovery. BHR to histamine was defined as a fall in $\mathrm{FEV}_{1}$ of $20 \%$ or more following histamine challenge.

The water content of the inspired air was $<10 \mathrm{mg} \mathrm{H} \mathrm{H}_{2} \mathrm{O} \cdot l^{-1}$ for all tests (mean 7.7, range 6.4-9.7 $\mathrm{mg} \mathrm{H} \mathrm{H}_{2} \mathrm{O} \cdot l^{-1}$ ), the mean temperature was $13^{\circ} \mathrm{C}$ (range $11-16^{\circ} \mathrm{C}$ ) and the mean relative humidity was $66 \%$ (range $57-71 \%$ ).

\section{Respiratory Symptoms}

Each child returned a questionnaire, completed by a parent or guardian, which collected demographic information and details of respiratory illness history. The questions of wheeze were "Has your child ever wheezed (Wheezing is a whistling noise that comes from the chest)?"; "If yes, was this in the last 12 months?"; "Has your child ever had wheezing during or after exercise?"; "If yes, was this in the last 12 months?" The question for diagnosed asthma was "Has your child ever been diagnosed as having asthma by a doctor or at a hospital?".

\section{Skin prick tests}

Atopy was measured by skin prick test reactions to allergens (Hollister-Stier, Miles Inc., Elkhart, IN, USA) applied to the forearm [21]. Histamine and glycerol were used as positive and negative controls but no child had a negative histamine or a positive control. After 15 minutes, wheal size was recorded as the long axis and its perpendicular; mean wheal size was used in analyses. A skin prick reaction was regarded as positive if the wheal size was $3 \mathrm{~mm}$ or greater. Allergens tested were: house dust, Dermatophagoides farinae, Dermatophagoides pteronyssinus, rye grass, plantain, cockroach, cat dander and Alternaria tenuis. Atopy was defined as a positive skin prick test reaction to one or more allergens.
Analysis

Data were analysed using the statistical package SAS (SAS Institute Inc., Cary, NC). Both $\%$ fall in $\mathrm{FEV}_{1}$ following exercise and dose-response ratio (DRR) to histamine are continuous measures which could be calculated for all subjects.

Exercise response was recorded as the greatest fall in $\mathrm{FEV}_{1}$ following exercise, expressed as a percentage of the baseline $\mathrm{FEV}_{1}$, i.e. Exercise response $=\left(\right.$ fall in $\mathrm{FEV}_{1} /$ baseline $\left.\mathrm{FEV}_{1}\right) \times 100$.

Histamine response was expressed as DRR calculated as the percentage fall in $\mathrm{FEV}_{1}$ at last dose divided by the total dose administered [22].

$\mathrm{DRR}=\left(\%\right.$ fall in $\mathrm{FEV}_{1}$ (last dose $) /$ total dose histamine umol) +3 .

Because DRR values are log normally distributed [23] they were converted to base 10 logarithms prior to analyses. Thus, in order to return a positive value for logarithmic conversions, DRR values had a constant of 3 added and are indicated by units $\%$ fall $\mathrm{FEV}_{1} / \mu \mathrm{mol}+3$ [23]. Ranges given for mean values are expressed with the $95 \%$ confidence interval (CI), SD or absolute range. Pearson's correlation coefficient and linear regression were used to compare the continuous measures of response to the exercise and histamine challenges.

\section{Results}

The children ranged in age from 7-12 years with a mean age of 9 years (SD 0.9). The mean height was $137.1 \mathrm{~cm}$ (SD 8.2) and mean weight was $33.2 \mathrm{~kg}$ (SD 7.6). Forty-nine percent of the sample were female and $98 \%$ were Caucasian. Eighteen children had used bronchodilators and/or inhaled corticosteroids at some time in the past month.

The exercise challenge was easy to conduct and six research assistants were able to test all of the children in less than two school days (9am-3pm) using four spirometers. The between-observer variability in $\%$ fall in $\mathrm{FEV}_{1}$ was not significant $\left(\mathrm{F}_{5,89}=0.14 ; \mathrm{p}=0.98\right)$. All of the research assistants had extensive experience in measuring lung function in children prior to this study. One child panicked and failed to complete the test but did not have respiratory symptoms. All other children completed the test without any problems.

The mean distance completed was 879 (SD 131) m which is equivalent to a mean oxygen consumption of 36.6 (SD 4.0) $\mathrm{ml} \cdot \mathrm{kg}^{-1} \cdot \mathrm{min}^{-1}$ [19] and the mean heart rate was 191 (SD 7.7) bpm. These values were higher than expected and indicate excellent compliance with the exercise test. Most children reached the required heart rate within the first minute of running (mean heart rate at one minute was 188 (SD 8.7) bpm). Four children had an oxygen consumption over the $6 \mathrm{~min}$ of running of less than $30 \mathrm{ml} \cdot \mathrm{kg}^{-1} \cdot \mathrm{min}^{-1}$ but higher than $26 \mathrm{ml} \cdot \mathrm{kg}^{-1} \cdot \mathrm{min}^{-1}$ although their mean heart rate was higher than $180 \mathrm{bpm}$. Also, one child had a mean heart rate of $161 \mathrm{bpm}$ but an oxygen consumption of 33 $\mathrm{ml} \cdot \mathrm{kg}^{-1} \cdot \mathrm{min}^{-1}$. These children were included in the analyses because they satisfied at least one of the two intensity criteria. 
The mean fall in $\mathrm{FEV}_{1}$ plus $1.96 \mathrm{SD}$ in subjects without diagnosed asthma, recent wheeze or atopy $(n=38)$ was $13 \%$. Therefore, a fall in $\mathrm{FEV}_{1}$ of $13 \%$ or more at any time following exercise was chosen as our criteria for bronchial hyperresponsiveness (BHR) to exercise.

Table 1. - Relation between response to exercise challenge and to histamine challenge

\begin{tabular}{lcc}
\hline BHR to exercise & \multicolumn{2}{c}{ BHR to histamine } \\
& positive & negative \\
\hline positive & 5 & 6 \\
negative & 6 & 77 \\
\hline
\end{tabular}

BHR: bronchial hyperresponsiveness; positive: a fall in $\mathrm{FEV}_{1}$ of $\geq 20 \%$ following histamine challenge and $\geq 13 \%$ following exercise challenge. $\mathrm{FEV}_{1}$ : forced expiratory volume in one second.

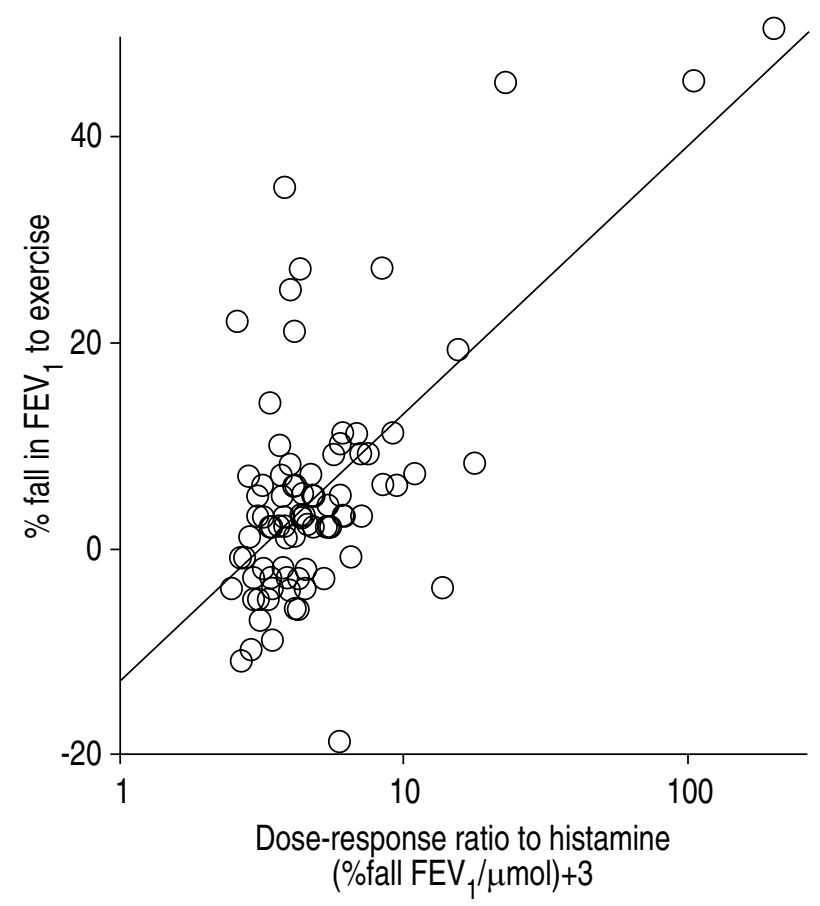

Fig. 2. - Relationship between dose-response ratio to histamine (log scale) and \% fall in $\mathrm{FEV}_{1}$ to exercise, shown with the regression line. $\mathrm{FEV}_{1}$ : forced expiratory volume in one second.
Table 1 shows that some children reacted to one challenge and not to the other, although the number of children who had a positive response to exercise challenge and to histamine challenge was the same $(12 \%)$. When "current asthma" is defined as recent wheeze plus BHR, the number of children who had 'current asthma (exercise)' was the same as for 'current asthma (histamine)' (7\%). However, these cannot be regarded as prevalence figures because the sample studied was not randomly selected.

The two measures of responsiveness to exercise and histamine were compared (figure 2) using continuous measures of $\%$ fall in $\mathrm{FEV}_{1}$. For the histamine challenge only, this was adjusted for dose of histamine administered. Agreement between the two tests was 0.87 (CI 0.80, 0.94) [24] and Pearson's correlation coefficient $(r)$ was $0.65(\mathrm{p}=0.0001)$. The regression was greatly influenced by the three children with the most severe responsiveness. For $\%$ fall $\mathrm{FEV}_{1}$ values $<40$, the DRR varied between 2 and $20 \%$ fall in $\mathrm{FEV}_{1} / \mathrm{\mu mol}+3$. In the three children with $\%$ fall in $\mathrm{FEV}_{1}$ values $>40$, the DRR fell by more than $20 \%$ fall $\mathrm{FEV}_{1} / \mu \mathrm{mol}+3$.

Exercise and histamine challenge were compared to diagnosed asthma, recent wheeze and atopy (table 2). For both challenges the specificity was high (0.94-0.95) which means that only $5-6 \%$ of subjects without diagnosed asthma, recent wheeze or atopy had BHR. For both challenges the sensitivity was low $(0.23-0.27)$ which means that only $23-27 \%$ of subjects with diagnosed asthma, recent wheeze or atopy had BHR. Because the values for proportion in agreement, sensitivity and specificity were similar for both challenges this suggests that they have the same construct validity, although the numbers may be too small to make definitive conclusions.

\section{Discussion}

This is the first study to compare exercise and histamine challenges in children tested in an epidemiological setting. Histamine challenge tests have an excellent safety record in epidemiological studies but alternative challenges are sometimes required. The exercise challenge was simple to conduct, did not cause any side-effects, had an excellent compliance rate and was apparently enjoyed by both subjects

Table 2. - A comparison of exercise and histamine response to other data relating to asthma

\begin{tabular}{cccc}
\hline & Sensitivity & Specificity & $\begin{array}{c}\text { Proportion in } \\
\text { agreement }(95 \% \mathrm{CI})\end{array}$ \\
\hline $\begin{array}{c}\text { Diagnosed asthma (n=30) } \\
\text { BHR to exercise }\end{array}$ & 0.27 & 0.95 & $0.73(0.64,0.82)$ \\
BHR to histamine & 0.23 & 0.94 & $0.71(0.62,0.80)$ \\
Recent wheeze (n=26) & & & $0.76(0.67,0.84)$ \\
BHR to exercise & 0.27 & 0.94 & $0.76(0.67,0.84)$ \\
BHR to histamine & 0.27 & 0.94 & \\
Atopy (n=34) & & & $0.69(0.59,0.78)$ \\
BHR to exercise & 0.24 & 0.95 & $0.69(0.59,0.78)$ \\
BHR to histamine & 0.24 & 0.95 &
\end{tabular}

BHR: bronchial hyperresponsiveness; CI: confidence interval; Recent wheeze: wheeze or exercise wheeze in the 12 months before study. 
and observers. When compared to recent wheeze, diagnosed asthma and atopy, exercise challenge had similar sensitivity and specificity as the histamine challenge. The comparison of results from different challenge tests and from different populations is important for studies which aim to elucidate the mechanism of asthma in children or to measure the risk factors which influence prevalence. The results confirm that the exercise challenge described could be used as a standard and sensitive tool for comparing bronchial responsiveness in populations of children.

The samples were not biased in terms of children who had used an asthma medication in the last month preferentially attending or declining to attend for either challenge, and the full range of asthma severities found in the general population was represented. The questions used in this study to measure symptoms have good repeatability [25], as have both the skin test method [26] and the histamine challenge method when used in the field [27].

We used an exercise challenge protocol based on a previously standardised clinical challenge [8] which we adapted both to overcome some of the perceived limitations of previously reported exercise tests used in the field [10-14] and to maximise responsiveness. We used $\mathrm{FEV}_{1}$ to measure changes in lung function because this measurement has less within-subject variability than PEF $[15,16]$ and reflects a larger proportion of the flow-volume curve than PEF [9]. Also, in practical terms, spirometers are more suitable for testing large numbers of children in a short period of time than peak flow meters which collect moisture and cannot be calibrated accurately. We measured lung function at 3, 5 and $10 \mathrm{~min}$ post-exercise because GODFREY et al. [28] found that the greatest fall in lung function following exercise is likely to occur between 2 and $10 \mathrm{~min}$.

A potential limitation to exercise testing is the inability to standardise minute ventilation during exercise. To overcome this, we used two indirect measures of minute ventilation - heart rate and oxygen consumption. Continuous monitoring of heart rate gave immediate feedback of intensity, which we used to encourage some children to run faster if necessary or to advise unfit children to walk if exhaustion was evident. These data showed that all of the children ran at approximately $90 \%$ of their maximum heart rate and this level was usually achieved within the first minute of running. The majority of children were easily able to comply with the intensity requirement of the challenge. Measurement of total distance run in six minutes enabled us to estimate oxygen consumption and confirmed that all but four children had run at a suitable intensity, i.e. between 30 and $45 \mathrm{ml} \cdot \mathrm{kg}^{-1} \cdot \mathrm{min}^{-1}$, as recommended by ANDERSON [17]. Because the mean heart rate of each of these four children was greater than $180 \mathrm{bpm}$, they were included in analyses.

Since exercise challenge is thought to provoke airway narrowing by drying the airways [29], all subjects wore nose clips to enforce mouth breathing and, theoretically, to increase the responsiveness of the airways to the exercise challenge [9]. We used free-range running exercise for 6 min duration as used in other epidemiological protocols for exercise challenge [10-14] because this is the most effective for provoking BHR to exercise [8].

The ability of the exercise challenge to provoke airway nar- rowing is affected by the absolute water content of the inspired air [30], so that it is essential to monitor temperature and relative humidity to ensure that the water content of the inspired air is below $10 \mathrm{mg} \mathrm{H}_{2} \mathrm{O} \cdot l^{-1}$, which is the recommended maximum [17]. On study days, the absolute water content was less than $10 \mathrm{mg} \mathrm{H}_{2} \mathrm{O} \cdot l^{-1}$. An absolute water content above this is thought to reduce the sensitivity to exercise [18]. In practice, it was necessary to postpone testing on one day due to rain and subsequent high relative humidity. The criteria we used for BHR to exercise was a fall in $\mathrm{FEV}_{1}$ of $13 \%$ or more following exercise challenge. This was calculated by the statistically rigourous method of determining the upper limit of normal for \% fall in $\mathrm{FEV}_{1}$, namely a value equal to 1.96 standard deviations above the mean \% fall in $\mathrm{FEV}_{1}$ in the 'normal' subjects. 'Normal' was defined as subjects without diagnosed asthma, recent wheeze or atopy. This method was also used by GoDFrey et al. [7] and KATTAN et al. [31] who obtained values of $8.2 \%$ and $10 \%$ fall in $\mathrm{FEV}_{1}$, respectively. Other authors chose arbitrary values of $10 \%$ [14], 15\% [12] or 20\% [3] fall in $\mathrm{FEV}_{1}$ or PEF. Further studies of larger population samples will allow accurate cut-off points for abnormality to be calculated.

In previous epidemiological studies of bronchial responsiveness in children, we have used histamine challenge because it is easy to administer and the results are both reliable and a good discriminator of symptom history [20, 23, 27]. Exercise may prove to be an alternative challenge for epidemiology studies because it is feasible, acceptable and reliable. Although exercise and inhalation (histamine, methacholine) challenges have been compared in relatively small samples studied in the laboratory [3-7], these studies have used only well defined 'asthmatics' and 'normals', in whom the diagnosis was not in question. No previous comparisons between exercise and histamine have been conducted in the field, in subjects with a full range of severity of asthma, or in subjects in whom the diagnosis was in doubt. Laboratory studies have found that exercise challenge is generally more specific but less sensitive for diagnosed asthma compared to histamine or methacholine challenge [5, 7].

Clinical studies have found that exercise challenge and histamine or methacholine challenge do not always identify the same individuals $[3,4,6]$. We also found that some children responded to one challenge but not to the other, which suggests that the two challenges identify different abnormalities of the airways. It has been suggested that BHR to exercise is due to the release of mast cell mediators such as histamine [29], thus response to exercise would depend both on the ability of the mast cells to release histamine and on the ability of the airways to respond to histamine. This may explain why some children responded to histamine but not exercise. However, based on this explanation, it would be expected that all subjects responding to exercise would also respond to histamine. The fact that 6 children responded to exercise but not histamine suggests that mediators other than histamine may be more important in BHR to exercise or that an additional, non-mast cell mechanism may be involved in BHR to exercise [32]. In contrast to laboratory studies, we found exercise challenge to have similar sensitivity and specificity for diagnosed asthma, recent wheeze and atopy compared to histamine challenge. 
Although the exercise challenge appeared useful for epidemiology, it has potential limitations. First, the dependence of the response to exercise challenge on the inspired air conditions may make it unsuitable in some climatic regions. However, this challenge could be conducted in indoor, airconditioned facilities. Also, the effects of very low water content (e.g. $\left.1 \mathrm{mg} \mathrm{H}_{2} \mathrm{O} \cdot l^{-1}\right)$ are unknown, but if this increases the response to the exercise challenge, it would need to be taken into account. Secondly, exercise challenge is unlikely to be suitable for use in epidemiological studies of adults. Although we found 8-11 year olds to be very compliant with this challenge, older children may be more susceptible to peer group pressure and may be less fit. Thirdly, it is difficult to compare exercise challenge directly with inhalation challenge (e.g. histamine or methacholine) because there is no 'dose-response' relationship with exercise challenge. Subjects undergoing exercise challenge receive a maximal provocative dose of exercise, i.e. 6 minutes at $90 \%$ of their maximum heart rate.

Although our preliminary findings with exercise challenge are encouraging, the results require further validation in a larger random sample, including comparison with respiratory symptoms and other recognised markers of asthma severity, such as wheeze frequency, morbidity and medication use. The repeatability of exercise challenge in field studies also needs to be determined and the cut-off for an abnormal response to exercise that we used (13\% fall in $\mathrm{FEV}_{1}$ following exercise) requires confirmation as the most sensitive and specific point. However, we believe this exercise challenge protocol can be used as a standardized epidemiological tool for measuring bronchial responsiveness in populations of children where an alternative to inhalation challenges is required. Standardized protocols are important for use in studies to compare prevalence in different populations or to explore the aetiology of asthma.

Acknowledgements: We thank Allen and Hanburys, the National Health and Medical Research Council of Australia, the Asthma Foundation of New South Wales and the Community Health and Anti-Tuberculosis Association for funding this project. In addition, we thank the children who participated in the studies and the research assistants who helped to collect the data.

\section{References}

1. Sears MR, Jones DT, Holdaway MD, et al. - Prevalence of bronchial reactivity to inhaled methacholine in New Zealand children. Thorax 1986; 41: 283-289.

2. Peat JK, Mellis CM, Tovey E, Leeder SR, Woolcock AJ. Importance of house-dust mite and Alternaria allergens: an epidemiological study in two climatic regions of Australia. Clin Exp Allergy 1993; 23: in press.

3. Foresi A, Mattoli S, Corbo GM, Polidori G, Ciappi G. Comparison of bronchial responses to ultrasonically nebulized distilled water, exercise, and methacholine in asthma. Chest 1986; 90: 822-826.

4. Fourie PR, Joubert JR. - Determination of airway hyperreactivity in asthmatic children: a comparison among exercise, nebulized water, and histamine challenge. Pediatr Pulmonol 1988; 4: 2-7.

5. Mellis CM, Kattan M, Keens TG, Levison H. - Compar- ative study of histamine and exercise challenges in asthmatic children. Am Rev Respir Dis 1978; 117: 911-915.

6. Bhagat RG, Grunstein MM. - Comparison of responsiveness to methacholine, histamine, and exercise in subgroups of asthmatic children. Am Rev Respir Dis 1984; 129: 221-224.

7. Godfrey S, Springer C, Noviski N, Maayan Ch, Avital A. Exercise but not methacholine differentiates asthma from chronic lung disease in children. Thorax 1991; 46: 488-492.

8. Silverman M, Anderson SD. - Standardization of exercise tests in asthmatic children. Arch Dis Child 1972; 47: 882-889.

9. Sterk PJ, Fabbri LM, Quanjer PhH, et al. - Airway responsiveness: Standardized challenge testing with pharmacological, physical and sensitizing stimuli in adults. Eur Respir J 1993; 6 Suppl 16: 53-83.

10. Burr ML, Eldridge BA, Borysiewicz LK. - Peak expiratory flow rates before and after exercise in schoolchildren. Arch Dis Child 1974; 49: 923-926.

11. Burr ML, Butland BK, King S, Vaughan-Williams E. Changes in asthma prevalence: two surveys 15 years apart. Arch Dis Child 1989; 64: 1452-1456.

12. Barry DMJ, Burr ML, Limb ES. - Prevalence of asthma among 12 year old children in New Zealand and South Wales: a comparative survey. Thorax 1991; 46: 405-409.

13. Keeley DJ, Neill P, Gallivan S. - Comparison of the prevalence of reversible airways obstruction in rural and urban Zimbabwean children. Thorax 1991; 46: 549-553.

14. Terblanche E, Stewart RI. - The prevalence of exerciseinduced bronchoconstriction in Cape Town schoolchildren. $S$ Afr Med J 1990; 78: 744-747.

15. Cropp GJA. - The exercise bronchoprovocation test: Standardization of procedures and evaluation of response. $J$ Allergy Clin Immunol 1979; 64: 627-633.

16. Strachan DP. - Repeatability of ventilatory function measurements in a population survey of 7 year old children. Thorax 1989; 44: 474-479.

17. Anderson SD. - Methodology for identifying and assessing exercise-induced asthma. In: Fish J, Hargreave FE, Eds. Bronchial provocation tests. New York, Marcel Dekker 1993 (in press).

18. Hahn A, Anderson SD, Morton AR, Black JL, Fitch KD. A reinterpretation of the effect of temperature and water content of the inspired air in exercise-induced asthma. Am Rev Respir Dis 1984; 130: 575-579.

19. Silverman M, Anderson SD. - Metabolic cost of treadmill exercise in children. J Appl Physiol 1972; 33: 696-698.

20. Yan K, Salome C, Woolcock AJ. - Rapid method for measurement of bronchial responsiveness. Thorax 1983; 38: 760-765.

21. Pepys J. - Skin testing. Br J Hosp Med 1975; 14: 412-417.

22. O'Connor G, Sparrow D, Taylor D, Segal M, Weiss S. Analysis of dose-response curves to methacholine. An approach suitable for population studies. Am Rev Respir Dis 1987; 136: 1412-1417

23. Peat JK, Salome CM, Berry G, Woolcock AJ. - Relation of dose-response slope to respiratory symptoms in a population of Australian schoolchildren. Am Rev Respir Dis 1991; 144: 663-667.

24. Bland JM, Altman DG. - Statistical methods for assessing agreement between two methods of clinical measurement. Lancet 1986; 1: 307-310.

25. Salome CM, Peat JK, Britton WJ, Woolcock AJ. Bronchial hyperresponsiveness in two populations of Australian schoolchildren. I. Relation to respiratory symptoms and diagnosed asthma. Clin Allergy 1987; 17: 271-281. 
26. Peat JK, Salome CM, Woolcock AJ. - Longitudinal changes in atopy during a 4-year period: Relation to bronchial hyperresponsiveness and respiratory symptoms in a population sample of Australian schoolchildren. J Allergy Clin Immunol 1990; 85: 65-74.

27. Peat JK, Salome CM, Bauman A, Toelle B, Wachinger S, Woolcock AJ. - Repeatability of the histamine bronchial challenge and comparability with methacholine bronchial challenge in a population of Australian schoolchildren. Am Rev Respir Dis 1991; 144: 338-343.

28. Godfrey S, Silverman M, Anderson SD. - Problems of interpreting exercise-induced asthma. J Allergy Clin Immunol 1973; 52: 199-209.

29. Anderson SD. - Asthma provoked by exercise, hyper- ventilation, and the inhalation of nonisotonic aerosols. In: Barnes PJ, Rodger IW, Thomson NC, Eds. Asthma: Basic mechanisms and clinical management (2nd Edition). London, Academic Press Ltd, 1992; 473-490.

30. Anderson SD, Schoeffel RE, Black JL, Daviskas E. Airway cooling as the stimulus to exercise-induced asthma - a re-evaluation. Eur J Respir Dis 1985; 67: 20-30.

31. Kattan M, Keens TG, Mellis CM, Levison H. - The response to exercise in normal and asthmatic children. $J$ Pediatr 1978; 92: 718-721.

32. Jarjour NN, Calhoun WJ, Stevens CA, Salisbury SM. Exercise-induced asthma is not associated with mast cell activation or airway inflammation. J Allergy Clin Immunol 1992; 89: 60-68. 